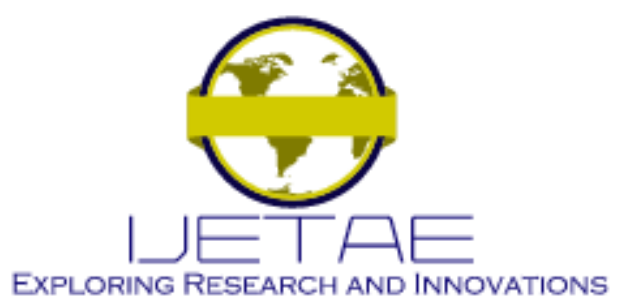

International Journal of Emerging Technology and Advanced Engineering

Website: www.ijetae.com (E-ISSN 2250-2459, Scopus Indexed, ISO 9001:2008 Certified Journal, Volume 11, Issue 11, November 2021)

Manuscript Received: 09 October 2021, Received in Revised form: 06 November 2021, Accepted: 11 November 2021

DOI: 10.46338/ijetae1121_21

\title{
Predictive Analysis of the Enrolment of Elementary Schools Using Regression Algorithms
}

\author{
Elizalde Lopez Piol ${ }^{1,1}$, Luisito Lolong Lacatan ${ }^{1,2}$, Jaime P. Pulumbarit ${ }^{2,3}$ \\ ${ }^{I}$ Department of Education - Philippines (DepEd) \\ ${ }^{2}$ College of Engineering, Laguna University, Philippines \\ ${ }^{3}$ Bulacan State University, Malolos Bulacan, Philippines
}

\begin{abstract}
By fitting a linear equation to observable values, linear regression determines the relationship between two variables. The Department of Education enrollment data in the Philippines, specifically in the School Division of Batangas, is needed to produce modules. The data collected is from the division office, where data cleaning was applied. Deep Learning, Decision Tree, Random Forest, Gradient Boosted Tree, Support Vector Machine, and Linear Regression were used to perform the prediction, and linear regression performed the best with an absolute value of 14.465 and a relative error of $84.81 \%$.
\end{abstract}

Keywords - Prediction, Information Management, Linear Regression, Cloud Computing, LDM.

\section{INTRODUCTION}

Department of Education (DepEd) has established Learning Delivery Modalities for their clients. As part of this, synchronous and asynchronous mode of learning [1] is also presented to the parents and students. The LDM implementation has continuously met the gap for the learners and teachers to acquire knowledge in a modular arrangement. Most of the learning materials are gathered through a Cloud Computing (CC), the Information Management model [2]. However, the learning materials are still evaluated to see if the modules adequately assess students' understanding of a particular area. Moreover, there is a need to assess the learners' success in all grade levels and across domains.

In the presence of the COVID-19, the LDM produced a solution to continue the educations of the learners. The elementary and high school elementary and high school students implemented the distribution of modules to the learners that have to be accomplished per week. Other institution also prepared for the synchronous and asynchronous model of learning which depends on the type of system applied for upon enrollment.
Two major difficulties arise from the implementation of the program such as no means of computer or smartphone and some have difficulty in internet connection. For the implementation of learning modules; excessive or lacking number of printed learning modules, damaged modules due to wear and tear, and others.

A model will be proposed to evaluate the process of allocating learning resources and the resources required by the various schools in DepEd Region 4A [3], which comprises 21 Divisions. The study will concentrate on the prediction of the province of Batangas for the elementary education department, starting from Kindergarten to Grade 6 only with the coverage of the academic year of 20162017 until the academic year 2019-2020. A prediction based on linear regression was used to measure each institution's performance and success rate using cloudbased learning resources [4]. Furthermore, analyzing the trend of the different data collected from various sources and determining the acceptability of cloud-based learning.

Different predicting models had been used in different studies like gradient boosted tree [5], naive Bayes, random forest, and others; however, these models may not be appropriate in predicting enrollment of primary schools in region $4 \mathrm{a}$. With the different trends and pandemics, it will be harder to predict this dilemma's enrollment pattern [6]. The research will be more accurate by determining the different parameters and the best fit predictive algorithm.

One of the leading predictive algorithms is Regression [7] ; this algorithm has been used in medical, statistical, environmental predictions, and even enrollment analysis [8][9]. It has also been proven that the regression algorithm fits multidimensional datasets [10]. In this case, using this method would allow a broader scope with higher accuracy [11]. 


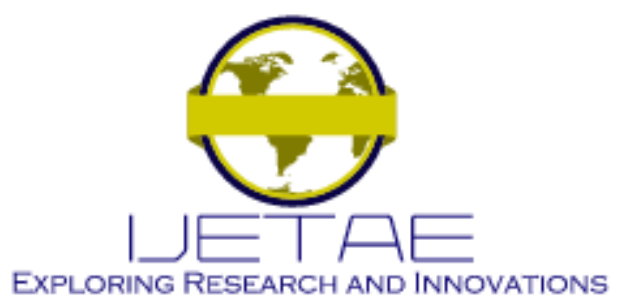

International Journal of Emerging Technology and Advanced Engineering

Website: www.ijetae.com (E-ISSN 2250-2459, Scopus Indexed, ISO 9001:2008 Certified Journal, Volume 11, Issue 11, November 2021)

Linear regression is fitted for the dataset for it depends on other variables in line with time series. Works best with the enrollment prediction since each year creates a trend that would be the basis of a good predictor result.

Applying a regression approach in a cloud computing environment [12] would be a more significant challenge, but the possibility of integration would show the study's novelty.

\section{DATA PREPARATION}

The data was collected in the different district offices of the Cavite, Laguna, Batangas, Rizal, and Quezon (CALABARZON) Area but will only concentrate on the elementary education of the Schools Division of Batangas Province.

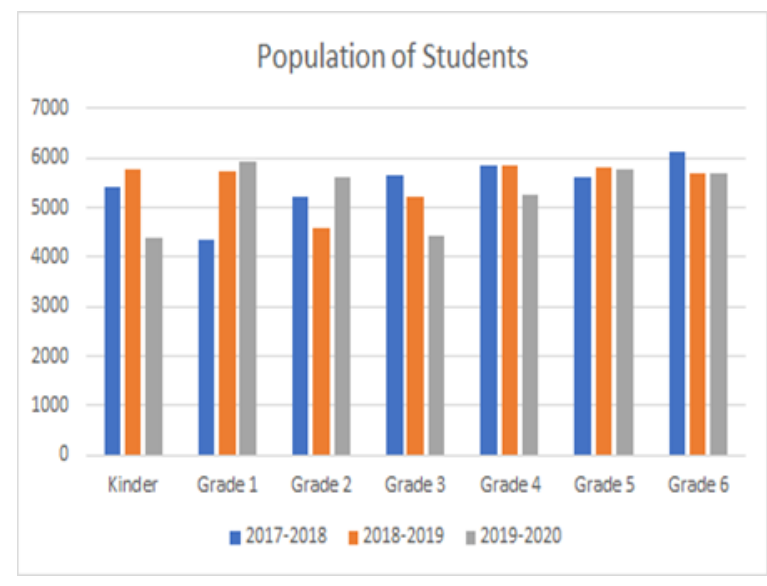

Figure 1. Distribution OF THE POPULATION IN ELEMENTARY EDUCATION OF BATANGAS

The distribution of data for the province of Batangas for elementary education is for the three consecutive academic years. This data will be used to predict the next academic year by using the trend and linear regression.

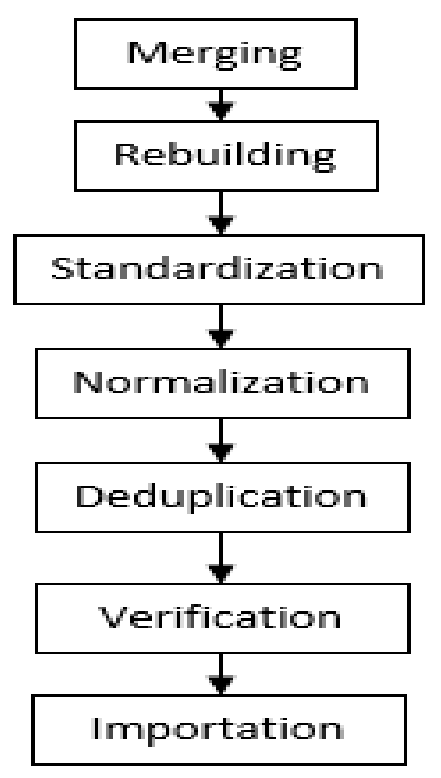

Figure 2. Steps on Data Cleaning

In line with the data collection is the preparation for data cleaning. The different data representations collected will be merged to a single dataset hat would represent the total students to receive a learning module. The data must be rebuilt to check if the fields are complete or has different datatypes, in this process, the completion of data is important for the data preparation. The data must be standardized so that it follows the same datatype and input patterns, having the same field size and determined values of input is important in the preparation of data. The data must be normalized to determine the significance of the data and relationship to each other. Deduplication is done to remove the redundant values in the table which would make the prediction process invalid. Verifying the legitimacy of each entry is done to determine if the values is a sustainable data that would support other data. Lastly, importation is needed in the process to establish the cleaned data and ready for prediction. 


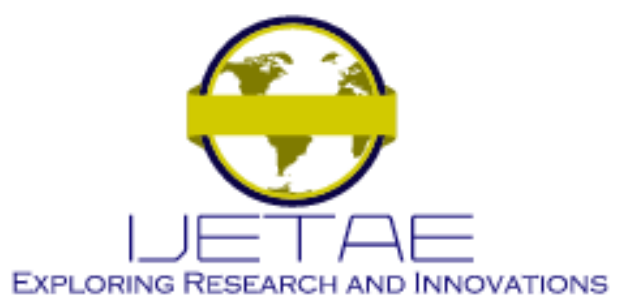

International Journal of Emerging Technology and Advanced Engineering

Website: www.ijetae.com (E-ISSN 2250-2459, Scopus Indexed, ISO 9001:2008 Certified Journal, Volume 11, Issue 11, November 2021)

\section{METHODS}

The methods contain different stages, from the preparation of data to model generation for different predictions. The data will run in different algorithms; a simultaneous process will stimulate the best prediction model [13]. This strategy will compare the accuracy of each model that will be used.

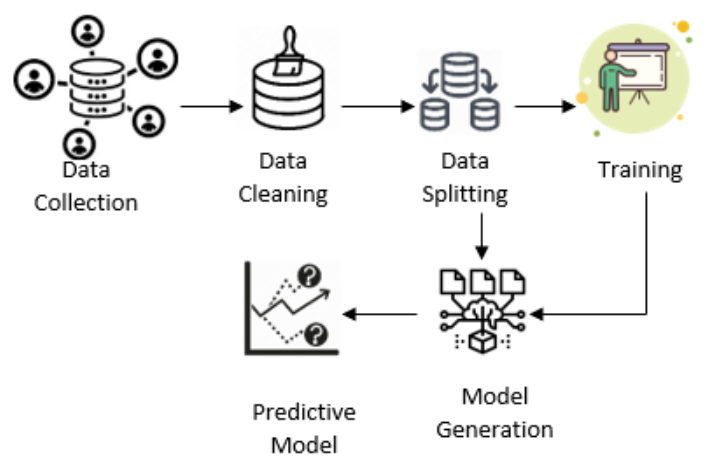

Figure 3. Methodology Of PREDiCtive Model Generation

The research will focus on the different layers of the process. The data collection process involves the Division office of CALABARZON collecting the number of enrollees per year and per level of the different districts. Data cleaning is the preparation of the data in terms of the process involving unique data per item. A data splitting technique was used to separate the training and testing dataset. The training data is set to seventy (70\%) and the testing data is set to thirty $(30 \%)$ [14]. Training is the processing of the data cleansed to create a model. This model will determine the flow of the data if it will obtain a higher accuracy rate specifying the relative error and the absolute value. The relative error is the measure of precision which is coordinated with the size of the item [15]. The model generation will accept two specific data, one is the trained dataset, and the other one is the testing dataset. It would test the model's absolute error with the leniency of plus/minus percentage, the computation of the [3]. The analysis phase is the generated predictive model; it has been noted that different algorithms have different results depending on the dataset used [16] . Determining the predictive model that would be used will be based on the accuracy rate of the algorithm as it was applied to the dataset. [17]

\section{RESUlts AND Discussion}

Linear regression must state that all values must be set to numerical counterparts evaluated to predict the enrollees for the academic year 2020-2021 for DepEd Batangas Province.

The data was split into a coefficient of 70 percent and 30 percent for training and testing dataset with random values. The result of the prediction with the average number of values is presented in the table below. The average values represent the closest prediction for the dataset.

TABLE 1.

The Statistic AND average OF The Value and Predicted values.

\begin{tabular}{|l|l|l|l|}
\hline Name & Min & Max & Average \\
\hline Total & 1 & 175 & 34.402 \\
\hline Prediction & 3.304 & 139.773 & 34.591 \\
\hline
\end{tabular}

The range of values for the total and the prediction is closely related but for the values of the minimum and the maximum values has a significant range. The specific values contain the prediction which varies from the three consecutive academic years; hence, the prediction follows the pattern of the assumption of the incoming kindergarten based on the trend.

Based on the findings, the actual data is represented by green in figure 4, while blue is the prediction. The prediction has overlapped the actual data based on the training data and assumed more students would enroll for the upcoming academic year.

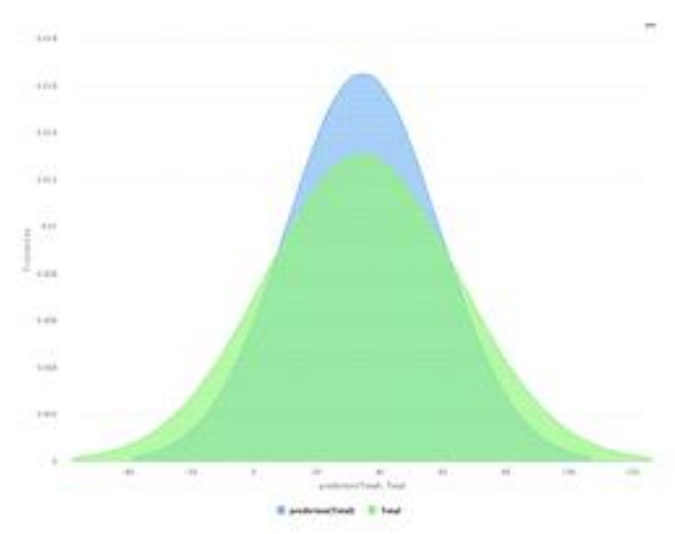

Figure 4. Bell Curve Representation 


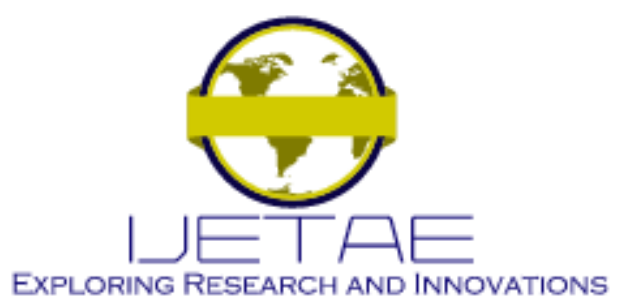

International Journal of Emerging Technology and Advanced Engineering

Website: www.ijetae.com (E-ISSN 2250-2459, Scopus Indexed, ISO 9001:2008 Certified Journal, Volume 11, Issue 11, November 2021)

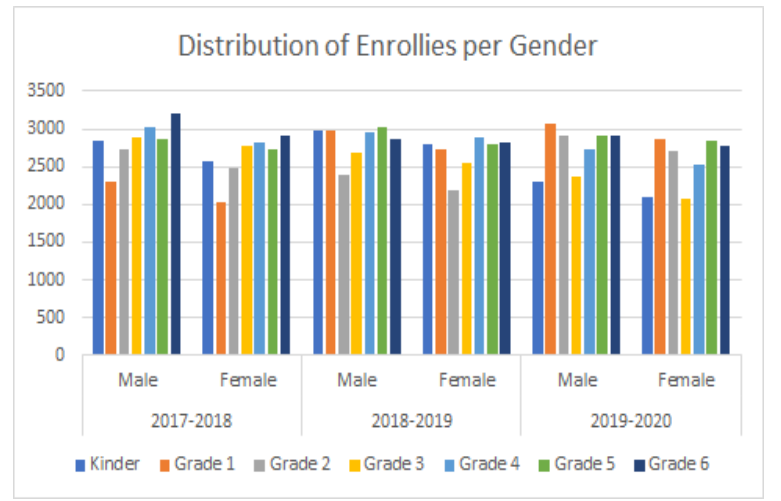

Figure 5. Distribution of Enrollees

One of the main parameters in the prediction is gender. The viability of prediction is based on the statistical value of each parameter; thus, the strength of the dataset will show the relationship of each predictive value shown in figure 5 .

Table 2.

Comparative Results

\begin{tabular}{|l|l|l|l|l|}
\hline Model & $\begin{array}{l}\text { Absolute } \\
\text { Error }\end{array}$ & $\begin{array}{l}\text { Relative } \\
\text { Error } \\
(\%)\end{array}$ & $\begin{array}{l}\text { Training } \\
\text { Time } \\
(\text { milli } \\
\text { seconds })\end{array}$ & $\begin{array}{l}\text { Scoring } \\
\text { Time } \\
\text { (milli } \\
\text { seconds) }\end{array}$ \\
\hline Deep Learning & 23.106 & 49 & 2000 & 10 \\
\hline Decision Tree & 23.364 & 49 & 6 & $\sim 0$ \\
\hline Random Forest & 23.368 & 49 & 1 & $\sim 0$ \\
\hline $\begin{array}{l}\text { Gradient Boosted } \\
\text { Tree }\end{array}$ & 23.398 & 49 & 84 & 85 \\
\hline $\begin{array}{l}\text { Support Vector } \\
\text { Machine }\end{array}$ & 21.615 & 47.4 & 1000 & 869 \\
\hline $\begin{array}{l}\text { Linear } \\
\text { Regression }\end{array}$ & 14.465 & 84.81 & 320 & 100 \\
\hline
\end{tabular}

The dataset had been tested to different algorithms to compare the best model to apply. Based on the results, linear regression has the lowest absolute error compared with five other algorithms. They are obtaining 14.465 and 7.15 points higher compared to the nearest algorithm, which supports vector machines. While the relative error shows that the support vector machine performed better than Linear regression, the values of the enrollees show small values making the difference minimal. The relative error of the linear regression is $84.81 \%$ which fits the prediction.

\section{RECOMMENDATION}

Integration of another neighboring municipality to predict the enrollment of the Region 4A is recommended. This is to determine the predicted number of the printed modules to be used in each school. Also include the junior high and Senior high of the region for future study.

\section{REFERENCES}

[1] M. M. Shahabadi and M. Uplane, "Synchronous and Asynchronous e-learning Styles and Academic Performance of e-learners," Procedia - Soc. Behav. Sci., vol. 176, pp. 129-138, 2015, doi: 10.1016/j.sbspro.2015.01.453.

[2] M. Chamilco, A. Pacheco, C. Peñaranda, E. Felix, and M. Ruiz, "Materials and methods on digital enrollment system for educational institutions," Mater. Today Proc., no. xxxx, pp. 2-6, 2021, doi: 10.1016/j.matpr.2021.04.213.

[3] E. Jimenez and Y. Sawada, "Public for private: The relationship between public and private school enrollment in the Philippines," Econ. Educ. Rev., vol. 20, no. 4, pp. 389-399, 2001, doi: 10.1016/S0272-7757(00)00061-3.

[4] P. Singh and Y. P. Huang, "A new hybrid time series forecasting model based on the neutrosophic set and quantum optimization algorithm," Comput. Ind., vol. 111, pp. 121-139, 2019, doi: 10.1016/j.compind.2019.06.004.

[5] M. D. Hernandez, A. C. Fajardo, and R. P. Medina, "A hybrid convolutional neural network-gradient boosted classifier for vehicle classification,” Int. J. Recent Technol. Eng., vol. 8, no. 2, pp. 213 216, 2019, doi: 10.35940/ijrte.B1016.078219.

[6] R. Bozick, D. M. Anderson, and L. Daugherty, "Patterns and predictors of postsecondary re-enrollment in the acquisition of stackable credentials," Soc. Sci. Res., vol. 98, no. April 2020, p. 102573, 2021, doi: 10.1016/j.ssresearch.2021.102573.

[7] L. L. Lacatan and G. M. Penuliar, "Competency-Based Mapping Tool in Personnel Management System using Analytical Hierarchy Process," 4th Int. Conf. Mach. Learn. Mach. Intell., 2021, doi: $10.1145 / 3490725.3490734$

[8] V. Vamitha, "A different approach on fuzzy time series forecasting model,” Mater. Today Proc., vol. 37, no. Part 2, pp. 125-128, 2020, doi: 10.1016/j.matpr.2020.04.579.

[9] M. A. Dela Cruz, "of State Universities and Colleges in Central Luzon Philippines :," 2019.

[10] A. Bender et al., "Dataset for multidimensional assessment to incentivise decentralised energy investments in Sub-Saharan Africa," Data Br., vol. 37, p. 107265, 2021, doi: 10.1016/j.dib.2021.107265.

[11] M. D. Hernandez, A. C. Fajardo, R. P. Medina, J. T. Hernandez, and R. M. Dellosa, "Implementation of data augmentation in convolutional neural network and gradient boosted classifier for vehicle classification,” Int. J. Sci. Technol. Res., vol. 8, no. 12, pp. 185-189, 2019. 


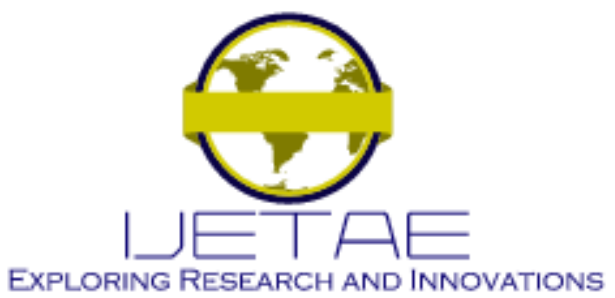

International Journal of Emerging Technology and Advanced Engineering

Website: www.ijetae.com (E-ISSN 2250-2459, Scopus Indexed, ISO 9001:2008 Certified Journal, Volume 11, Issue 11, November 2021)

[12] N. K. Biswas, S. Banerjee, U. Biswas, and U. Ghosh, "An approach towards development of new linear regression prediction model for reduced energy consumption and SLA violation in the domain of green cloud computing," Sustain. Energy Technol. Assessments, vol. 45, no. February, p. 101087, 2021, doi: 10.1016/j.seta.2021.101087.

[13] Alexen A. Elacio; Luisito L. Lacatan; Albert A. Vinluan; Francis G. Balazon, "Machine Learning Integration of Herzberg's Theory using C4.5 Algorithm ," Int. J. Adv. Trends Comput. Sci. Eng., vol. 9, no. 1.1, pp. 57-63, 2020, doi: 10.30534/ijatcse/2020/1191.12020.

[14] A. S. Alon, M. C. A. Venal, S. V. Militante, M. D. Hernandez, and H. B. Acla, "Lyco-frequency: A development of lycopersicon esculentum fruit classification for tomato catsup production using frequency sensing effect," Int. J. Adv. Trends Comput. Sci. Eng., vol. 9, no. 4, pp. 4690-4695, 2020, doi: 10.30534/ijatcse/2020/72942020.
[15] A. H. Ansari, "Collaboration or competition? Evaluating the impact of Public Private Partnerships (PPPs) on public school enrolment," Int. J. Educ. Res., vol. 107, no. February, p. 101745, 2021, doi: 10.1016/j.ijer.2021.101745.

[16] J. Z. Bantog, L. L. Lacatan, and M. A. F. Quioc, "Cross-Platform Relational Data Extraction Utilizing SQL Server (X-PRESS)," Int. J. Comput. Appl., vol. 183, no. 31, pp. 34-41, 2021, doi: 10.5120/ijca2021921703.

[17] S. J. R. Manglapuz and L. L. Lacatan, "Academic management android application for student performance analytics: A comprehensive evaluation using ISO 25010:2011," Int. J. Innov. Technol. Explor. Eng., vol. 8, no. 12, pp. 5085-5089, 2019, doi: 10.35940/ijitee.L2735.1081219. 